\title{
Startups e o consumo de comunicação: possibilidades por variáveis de influência em redes sociais digitais
}

\author{
Startups and the consumption of communication: possibilities for variables of \\ influence in social networks digital
}

\section{Startups y el consumo de la comunicación: las posibilidades para las variables de influencia en las redes sociales digital}

\author{
Laís Karla da Silva Barreto \\ Alípio Ramos Veiga Neto ${ }^{2}$ \\ Francisca Simonely de Vasconcelos ${ }^{3}$ \\ Raquel Priscyla da Silva Costa
}

\begin{abstract}
Resumo
O presente trabalho tem como objetivo identificar as variáveis de influência das redes sociais digitais no consumo de comunicação promovido pelas startups. O referencial teórico baseou-se no estudo das relações entre redes sociais digitais e comunicação, e análise conceitual e crítica das startups. A investigação se deu por estudo de casos múltiplos, no qual para obter as informações necessárias foram realizadas entrevistas semiestruturadas, aplicadas em ambiente virtual, com oito startups. Verificou-se que para identificar as variáveis se fez necessário a criação de três categorias, e destas originaram-se as seguintes variáveis: comunicação, relacionamento, divulgação, velocidade, clientes (internautas ou usuários), interatividade, abrangência, custo, diagnóstico, conteúdo, publicações e monitoramento. As respostas vindas das startups, contribuíram para entendimento sobre redes sociais digitais, startups e comunicação através das variáveis criadas por essa triangulação.
\end{abstract}

\begin{tabular}{|c|c|}
\hline & Acesse este artigo online \\
\hline \multirow{2}{*}{ 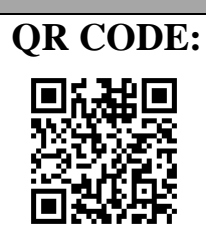 } & $\begin{array}{l}\text { Website: } \\
\text { http://www.revistas.ufg.br/index.php/ci }\end{array}$ \\
\hline & $\begin{array}{l}\text { DOI: } \\
\text { http://dx.doi.org/10.5216/ci.v20i2.46990 }\end{array}$ \\
\hline
\end{tabular}

Palavras-chave: Redes Sociais. Startups. Comunicação.Variáveis de influência.

\section{Abstract}

This study aims to identify the variables of influence of social networks in digital consumption of communication promoted by startups. The theoretical framework was based on the study of the relationship between social networks and digital communication, and

\footnotetext{
${ }^{1}$ Possui Doutorado e Mestrado pelo Programa de Pós-graduação em Estudos da Linguagem (UFRN) e especialização em Práticas Pedagógicas no Ensino Superior pela Universidade Potiguar. Integra o quadro docente do Mestrado Profissional em Administração da Universidade Potiguar. E-mail: laisbarreto@gmail.com

${ }^{2}$ Psicólogo com doutorado na área comportamental. Atualmente é Coordenador do Programas do Doutorado em Administração e docente permanente no Mestrado em Psicologia Organizacional da Universidade Potiguar (Natal). Consultor da CAPES para a área de Administração e membro do Conselho Técnico e Científico da FAPERN. E-mail: alipio@veiga.net

${ }^{3}$ MBA em Administração Financeira, pela UNIRN - Liga de Ensino do Rio Grande do Norte (2014). Diretora de Administração do IFRN/Campus Macau. E-mail: simonelyv@ hotmail.com

${ }^{4}$ Mestranda em Administração. Possui Pós-graduação em Gestão Estratégica de Negócios pelo Centro Universitário do Rio Grande do Norte (UNI-RN). Integra o quadro de servidores técnicos administrativos do Instituto Federal de Educação, Ciência e Tecnologia do Rio Grande do Norte - IFRN. E-mail: raquel.priscyla.mpa@gmail.com
}

Comun. \& Inf., Goiânia, GO, v. 20, n. 2, p. 45-58, jul./out. 2017 
conceptual analysis and criticism of startups. The research took place by multiple case study, in which to obtain the necessary information were performed semi-structured interviews, applied in a virtual environment, with eight startups.It was found that to identify the variables was made necessary the creation of three categories, and these have resulted in the following variables: communication, relationship, dissemination, speed, clients (users or users), interactivity, scope, cost, finding, content, publications and monitoring. The answers from the startups, have contributed to understanding on social networks, digital startups and communication through the variables created by this triangulation

Keywords: Social Networks. Startups. Communication. Variables of influence.

\section{Resumen}

El presente estudio pretende identificar las variables de la influencia de las redes sociales en consumo digital de comunicación promovidas por las startups. El marco teórico se basa en el estudio de la relación entre las redes sociales y la comunicación digital y el análisis conceptual y crítica de las startups. La investigación se realizó mediante el estudio de caso múltiple, en el que para obtener la información necesaria se realizaron entrevistas semi-estructuradas, aplicadas en un entorno virtual, con ocho startups. Se observó que para identificar las variables se hizo necesaria la creación de tres categorías, y estos se han traducido en las siguientes variables: la comunicación, la relación, la difusión, la velocidad, los clientes (o usuarios), la interactividad, el alcance, el coste, la búsqueda, el contenido de las publicaciones y la supervisión. Las respuestas de las startups, han contribuido a la comprensión de las redes sociales, startups digital y comunicación a través de las variables creadas por esta triangulación.

Palabras clave: Redes socials. Startups. Comunicación. Variables de influencia.

\section{INTRODUÇÃ̃O}

A Tecnologia da Informação tem provocado profundas mudanças em todo o mundo. Essas mudanças levaram ao crescimento e popularização da Internet. Segundo dados da União Internacional de Telecomunicações (UIT) em todo o mundo cerca de 3,2 bilhões de pessoas usam a Internet. Em 2000, quando líderes mundiais estabeleceram as Metas de Desenvolvimento do Milênio das Nações Unidas (ODM) eram apenas 400 milhões. Isso quer dizer que, nos últimos 15 anos, o alcance da Internet avançou de 6,5 para 43\% da população global. No Brasil, o Comitê Gestor da Internet afirma que mais da metade dos brasileiros são usuários da Internet (CAPUTO, 2014). Nessa perspectiva de avanços tecnológicos e com os mercados abertos, excluindo a ideia de locais fixos, o desenvolvimento das tecnologias de informação e comunicação abriu o mundo para qualquer organização.

Essa contínua conjuntura de avanços fez com que novos serviços surgissem através da Internet, desenvolvendo novas formas de comunicação. Entre eles destaca-se a difusão de redes sociais digitais - ambientes virtuais interativos onde os usuários trocam informações, contatos, experiências e opiniões. Reconhecendo essa tendência - e motivados pela rapidez, facilidade, abrangência, baixo custo e o alto nível de interatividade - empresas começaram a 
aderir a sites e aplicativos de redes sociais digitais, buscando aproximar-se de seus clientes, gerar vendas e lucro.

Assim, no mundo corporativo, grande parte das empresas passaram a utilizar as redes sociais como ferramenta de comunicação com clientes. Há de se convir que se as empresas têm de chegar aos seus clientes de forma eficaz, devem fazê-lo através da mídia que os clientes usam ativamente. Não obstante, as startups, conhecidas por sua criatividade, dinamismo e inovação aliaram-se às mídias digitais para promoção de seus negócios.

Nesse contexto, este artigo toma como referência a problemática das startups, redes sociais, e o consumo em comunicação, buscando resposta à seguinte pergunta: Quais as variáveis de influência das redes sociais digitais na comunicação das startups? Para responder tal questionamento buscou-se conhecer conceitos e opiniões sobre redes sociais, startups e comunicação, compreender a percepção das empresas quanto às redes sociais digitais, identificar suas razões para utilização e inteirar-se sobre suas estratégias de comunicação nas redes.

\section{REDES SOCIAIS DIGITAIS E A COMUNICAÇÃO}

Percebe-se que nos últimos anos, a Internet se expandiu e evoluiu para um sistema universal, no qual qualquer pessoa, previamente habilitada, pode conectar-se, acessar e partilhar dados. Essa transformação permitiu a difusão de ambientes virtuais interativos, onde os usuários trocam informações, experiências e opiniões. Segundo Dalmoro et at (2010), esses ambientes serviram como base para a evolução das redes sociais digitais. Nessa linha, Silva (2011), considera que esse passo evolutivo e natural, contribuiu para que tecnologias, comunicação e mídias ganhassem forma de redes.

Conforme explica Recuero (2009), uma rede social é definida como um conjunto de dois elementos: os atores, representados pelas pessoas, instituições ou grupos; e suas conexões, constituídas pelas interações ou laços sociais. Este modelo, permite afirmar que as redes sociais são formadas por um conjunto de perfis de usuários que interagem entre si, através do registro de informações e compartilhamento de dados, como fotos, mensagens e vídeos, além de expor características, hábitos, opiniões, sentimentos e preferências.

Para Cruz-Cunha et al (2012) no meio empresarial as redes sociais digitais são utilizadas para promover negócios, seja na interação e identificação de clientes e parcerias, como na pesquisa e expansão de mercados, no uso de campanhas de marketing, redução de custos e agilidade dos negócios. Nesse aspecto, Recuero (2009) sustenta que existem quatro 
valores básicos que permeiam o uso das redes sociais pelas empresas: (1) visibilidade, uma vez que os sites de redes sociais permitem maior conexão entre empresas e usuários; 2) reputação, referindo-se à percepção sobre o comportamento dos indivíduos ou empresas que influenciam nas decisões de ambos; 3) popularidade, relacionando-a à audiência, ou seja, a posição de um usuário dentro de sua rede social; e 4) autoridade, referindo-se ao poder de influência do usuário na rede social, decorrente também de sua reputação.

Dada a sua abrangência mundial, rapidez e velocidade com que propagam a informação, além de exporem características, hábitos e preferências de seus usuários, as redes sociais tornaram-se uma importante ferramenta de marketing. Nessa perspectiva, Coulter e Roggeveen (2012), destacam que cada vez mais as empresas estão se voltando para sites de redes sociais online como local importante para se estabelecer seu marketing. Isso porque, segundo Rocha et al (2011), as empresas podem utilizar as mídias sociais como instrumento para segmentar suas campanhas de acordo com o perfil dos usuários e comunidades existentes nas redes. Dessa forma, as mídias sociais passaram a fazer parte da estratégia de comunicação das empresas.

Além disso, Alvarenga (2014) registra que existem muitas oportunidades associadas às redes sociais virtuais, das quais estão: a criação de novos produtos e serviços; canais de colaboração e comunicação; ferramentas de marketing e publicidade; recrutamento de pessoal; melhor relacionamento com clientes, fornecedores e parceiros do negócio; percepção da marca; criação de reputação online; obtenção de feedback; redução de tempo e custos.

\section{STARTUP}

O empreendedorismo no Brasil se popularizou a partir dos anos 90, contudo, o empreendedorismo startup só passou a ser conhecido no país e executado por empreendedores brasileiros por volta de 1999 a 2001, período em que surgiu a bolha da internet, quando as empresas ".com” começaram a atuar no mercado eletrônico, segundo o especialista em startup, Gitahy (2011).

Gitahy (2011) ainda afirma que o assunto empreendedorismo, recentemente, tem se ampliado incluindo competitividade e desenvolvimento tecnológico nas empresas, incitado pela criatividade e pela inovação, o que estimula a criação de empresas com caráter inovador, compondo-se um papel importante no ambiente social a partir da criação de novos modelos de negócios. 


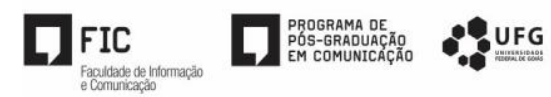

Startups estão vinculadas as atividades específicas para o avanço de uma instituição, como a realização de investimento em funcionários criativos, na organização de equipes e na criação de uma cultura organizacional que resulte em bons proveitos. $\mathrm{O}$ autor ainda aponta que a criação de um produto inovador compreende a agregação de valor em contato com um cliente e o impacto que o mesmo pode gerar, na qual a inovação é um diferencial para a organização.

De acordo com Gitahy (2011), startup é um tipo de empresa jovem, ou embrionária, em fase de construção de seus projetos, que está estreitamente associada à pesquisa, investigação e desenvolvimento de ideias inovadoras. Ele ainda acrescenta que startup é a formação de um grupo de pessoas que buscam um modelo de negócios repetível e escalável, trabalhando em condições de extrema incerteza. Ries (2012), apresenta a startup como um novo conceito de empreendedorismo, a qual preza pelo feedback contínuo. Em uma organização tradicional, recomenda-se fazer um plano detalhado para só depois ir ao mercado. Já nas startups, o indicado é validar a ideia para averiguar se tem mercado, se tem pessoas dispostas a consumir o produto (ALBERONE; CARVALHO; KICORVE, 2012). Trata-se de um feedback constante, tanto quantitativo como qualitativo, formando um ciclo, através das etapas construir, medir e aprender (RIES, 2012).

Segundo Tanenbaum (2010) o acesso à informação, comunicação interpessoal, entretenimento interativo e comércio eletrônico são finalidades de uso da Internet. Para Castells (2003) a Internet disponibiliza a comunicação em larga escala e, dessa forma, contribui no avanço das empresas, uma vez que permite que as empresas tenham escalabilidade; interatividade; administração da flexibilidade; uso de marca; e customização na rede. Quando fala de escalabilidade, o autor se refere à capacidade de desenvolvimento, expansão ou redução de acordo com a estratégia da empresa. A interatividade diz respeito ao em tempo real ou escolhido, com diversos stakeholders organizacionais, em um sistema multidirecional que contorna os canais verticais. A administração da flexibilidade, complementa o autor, consiste na possibilidade de combinar direção estratégica com interação múltipla e descentralizada com os stakeholders, a qual é decisiva para a consecução de metas estabelecidas. A marca diz respeito à possibilidade de um feedback de todos os componentes da rede no tocante aos seus processos e na detecção de erros. E por fim, ele afirma que a customização é a possibilidade de condução de negócios aproveitando as mudanças culturais e a diversidade de demandas globais. 


\section{PROCEDIMENTOS METODOLÓGICOS}

No intuito de identificar as variáveis de influência das redes sociais na comunicação das startups, o presente estudo propõe uma abordagem qualitativa, de caráter exploratório e descritivo. Para atender tal objetivo, foram realizadas pesquisas bibliográfica e documental, como também estudo de casos múltiplos. Quanto à coleta de dados decidiu-se conduzir entrevistas semiestruturadas, cujos dados foram tratados sob as práticas de análise de conteúdo.

A pesquisa preocupou-se em investigar os aspectos da realidade e pontos de vista subjetivos dos indivíduos pesquisados, focando na análise, compreensão e interpretação dos fenômenos, relações, motivações, experiências, interações e atitudes que envolvem a utilização das redes sociais na comunicação das startups, a fim de conhecer as variáveis do estudo (GERHARDT; SILVEIRA, 2009; FLICK, 2009).

Com o propósito de reunir o máximo de informações consistentes, permitindo maiores generalizações, como também um maior aprofundamento em busca da compreensão do objeto estudado, optou-se por realizar um estudo de casos múltiplos, no qual a escolha das empresas entrevistadas para compor o universo de investigação se deu por conveniência, em função da disponibilidade dos entrevistados (YIN, 2005).

Para obter as informações necessárias foram conduzidas oito entrevistas semiestruturadas realizadas em ambiente virtual. Dessa forma, permitiu-se recolher os dados descritivos na linguagem dos sujeitos, explorar seus pontos de vista e desenvolver intuitivamente uma ideia sobre a maneira com a qual interpretam os aspectos relacionados ao contexto de investigação (BOGDAN; BIFLEN, 2010). As entrevistas foram organizadas sob um roteiro com dez questões-chaves orientadas sob três categorias analíticas: 1) percepção dos entrevistados sobre as redes sociais digitais; 2) motivações para o uso das redes sociais digitais; e 3) estratégias de comunicação das empresas nas redes sociais digitais.

Com a finalidade de interpretar o material coletado, foi empregado o método de investigação entendido como análise de conteúdo. Para isso, conforme recomenda Bardin (2009), a pesquisa foi dividida em três etapas: 1) pré-análise, para organização do material, leitura flutuante da transcrição das entrevistas e demarcação do que seria analisado; 2) exploração do material, para codificar, classificar e categorizar o conteúdo; e 3) tratamento dos resultados, inferência e interpretação.

\section{ANÁLISE DOS RESULTADOS}

Comun. \& Inf., Goiânia, GO, v. 20, n. 2, p. 45-58, jul./out. 2017 
Participaram desta pesquisa oito startups, de diferentes regiões do país, cujas atividades envolvem a criação de aplicativos, softwares, lojas virtuais, interfaces gráficas, hospedagem de sites, sistemas web, geotecnologia, eventos, além do desenvolvimento de soluções inovadoras em diversas plataformas e tecnologias. As empresas estão no mercado há menos de cinco anos, possuem de dois a nove funcionários e todas utilizam pelo menos três redes sociais digitais, sendo as mais citadas o Facebook, Instagram, Linkedin, Twitter e WhatsApp.

As entrevistas foram organizadas sob um roteiro com dez questões principais orientadas com objetivo de revelar a percepção das startups quanto às redes sociais digitais, apontar as razões da utilização dessas redes, conhecer suas estratégias de comunicação para, por fim, identificar as variáveis de influência das redes sociais digitais na comunicação dessas empresas. Após organização dos dados, pôde-se categorizar, classificar e interpretar os dados, conforme sequência e Quadros I, II e III.

De maneira geral, para as startups entrevistadas, as redes sociais digitais são ambientes públicos de comunicação, nos quais é possível gerar e compartilhar informações e conteúdos de entretenimento e/ou comerciais de forma interativa. Observou-se também nas falas que, no meio empresarial, as redes sociais digitais exercem um papel fundamental no relacionamento com os consumidores, uma vez que as empresas utilizam estas redes para identificar, prospectar e fidelizar clientes, além de divulgar produtos e serviços da empresa a baixo custo e fechar negócios. O Quadro I mostra o resumo das respostas das startups sobre sua percepção a respeito das redes sociais digitais, nas quais foi possível identificar duas variáveis de influência: a comunicação e o relacionamento com os clientes.

Quadro I - Percepção sobre redes sociais digitais

$\begin{array}{ccl}\begin{array}{c}\text { Categoria } \\ \text { Percepção } \\ \text { sobre redes } \\ \text { sociais } \\ \text { digitais }\end{array} & \begin{array}{c}\text { Startup } \\ \text { A }\end{array} & \begin{array}{l}\text { Ideias centrais } \\ \text { Plataforma pública de relacionamento e geração de conteúdo pelos } \\ \text { usuários. Facilitador de vendas. } \\ \text { Ambiente comum de socialização, onde é possível comunicar-se } \\ \text { com cliente de todo o país a um custo viável. } \\ \text { Meio de comunicação simples, eficiente e mais acessível entre } \\ \text { empresa e clientes. }\end{array} \\ & \text { D } \quad \begin{array}{l}\text { Ferramenta de comunicação com a qual é possível prospectar } \\ \text { clientes. } \\ \text { Grupos digitais que trazem informações tanto comerciais quanto } \\ \text { entretenimento, os quais possibilitam a divulgação da empresa e o }\end{array}\end{array}$


fechamento de negócios.

F Espaço criado e utilizado através de dispositivos digitais, que viabilizam o entretenimento e a interação, otimizando o tempo do usuário na busca de informações e comunicações.

G Canal de relacionamento onde as pessoas criam perfis para manterem contato à distância. Ferramenta de extrema importância para se manter vivo no mercado de atuação.

H Ambiente para compartilhamento e divulgação de produtos e serviços para pessoas que estejam conectadas a elas, além de ser o local para identificação e fidelização de clientes.

Fonte: Dados da pesquisa (2016)

Nota-se, portanto, que as redes sociais digitais se apresentam como eficiente ferramenta para conectar empresas e clientes. Contudo, para entender e apontar as motivações que levam os empresários a utilizarem essa ferramenta, buscou-se junto às startups, suas razões e finalidades para o uso das redes digitais, conforme elencadas no Quadro II.

Dentre as razões mais mencionadas, destacam-se: $1^{\text {a }}$ ) divulgação da marca, produtos e serviços da empresa; $2^{\mathrm{a}}$ ) agilidade, velocidade e eficiência no processo de comunicação; $3^{\mathrm{a}}$ ) localização, captação e retenção de clientes; $4^{a}$ ) facilidade de acesso e espaço nas mídias; $5^{\mathrm{a}}$ ) interatividade com os clientes; $6^{\mathrm{a}}$ ) abrangência e viralização das publicações; $7^{\mathrm{a}}$ ) baixo custo;

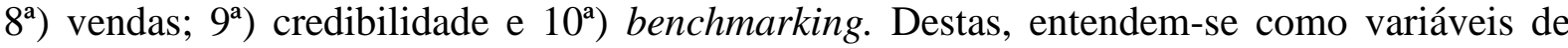
influência: divulgação, velocidade, clientes (internautas ou usuários), interatividade, abrangência e custo.

Quadro II - Motivações para o uso das redes sociais digitais

\begin{tabular}{|c|c|c|}
\hline Categoria & Startup & Ideias centrais \\
\hline \multirow{4}{*}{$\begin{array}{l}\text { Motivações } \\
\text { para o uso } \\
\text { das redes } \\
\text { sociais } \\
\text { digitais }\end{array}$} & $\mathrm{A}$ & $\begin{array}{l}\text { Solução de problemas dos usuários, branding, leads, vendas, } \\
\text { retenção de clientes. }\end{array}$ \\
\hline & B & $\begin{array}{l}\text { Facilidade de encontrar clientes em potencial. Disseminar conteúdo } \\
\text { relevante para os clientes. Converter leads qualificados em clientes. }\end{array}$ \\
\hline & $\mathrm{C}$ & $\begin{array}{l}\text { Custo baixo, acesso facilitado, interatividade, feedback } \\
\text { despretensioso, viralização, captação de novos clientes e } \\
\text { formadores de opinião, exibição de produtos, novidades e } \\
\text { tendências do mercado. }\end{array}$ \\
\hline & $\mathrm{D}$ & $\begin{array}{l}\text { Abrangência, velocidade, facilidade, baixo custo, divulgação de } \\
\text { produtos e interação com o público, visibilidade, credibilidade, } \\
\text { espaço nas mídias, interação com clientes e o mundo, } \\
\text { acessibilidade. }\end{array}$ \\
\hline
\end{tabular}


Velocidade na divulgação de informações e produtos, marketing mais acessível, abrangência, conhecimento de outras marcas e concorrentes em espaço curto de tempo.

F Facilita a divulgação em massa da empresa e dos produtos oferecidos, praticidade na atualização da página através de dispositivos móveis, baixo custo na divulgação das novidades, viabiliza o compartilhamento e marketing da empresa de forma eficiente, interação em tempo real com os clientes, captação de clientes que passaram a conhecer a empresa através das redes sociais e indicação de terceiros.

G Posicionamento de marca, relacionamento com o cliente, atração, apresentação do produto/serviço, diferenciais de atendimento (agilidade no processo de conversão), alcance, direciona o públicoalvo para o site, divulga produtos e serviços, agilidade, interação, gestão do tempo, automação.

H Divulgação e valorização da marca da empresa, captação de potenciais clientes, divulgação de produtos e serviços, disseminação de conhecimento, expansão das atividades da empresa além dos limites físicos (ex. cursos on-line), maior presença no ambiente virtual, abrangência, velocidade, maior facilidade e custo baixo para divulgação dos cursos oferecidos, benchmarking.

Fonte: Dados da pesquisa (2016)

Para a Startup "E" o mercado mudou muito e é preciso acompanhá-lo se adaptando a essas mudanças, principalmente às tecnológicas e reforça "se temos uma ferramenta de comunicação on line, praticamente gratuita, que atinge milhares de pessoas, temos que saber usá-las e divulgar forte nas mídias". A Startup "F" frisa que através da página no Facebook o nome da empresa ganhou maior visibilidade quando afirma que “ (...) com a indicação de amigos e clientes a página foi de 200 curtidas a 1250 em três dias. Assim a empresa atingiu um público maior em pouco tempo e sem custo". Já para a Startup "D” “existe um cuidado em responder prontamente às mensagens dos clientes e dar a devida atenção aos seus feedbacks", mostrando um diferencial no relacionamento com os clientes.

A partir das colocações citadas, é possível inferir que as startups utilizam as redes sociais como uma ferramenta de comunicação e canal de relacionamento com os clientes, fatores cruciais para imagem da empresa no mercado. Destacam-se, assim, no Quadro III, as principais estratégias de comunicação utilizadas nas redes sociais digitais pelas empresas entrevistadas.

Quadro III - Estratégias de comunicação nas redes sociais digitais 


Categoria
Estratégias
de
comunicação
nas redes
sociais
digitais

\section{Startup Ideias centrais}

A Utilização de personas. Atuação ativa. Publica conteúdo relevante para os clientes.

B Encontra clientes em potencial. Postagens com conteúdo relevante para o público alvo. Foca no início do processo de vendas. Converte visitantes da página em clientes.

C Publica novidades sobre produtos e serviços. Captação de novos clientes e formadores de opinião. Busca feedbacks dos envolvidos.

D A empresa faz publicidade de acordo com o perfil dos usuários e busca informações atuais para adaptar as campanhas. Divulgação dos produtos. Define-se os temas dos posts e frequência das publicações. Utiliza software de monitoramento.

E Analisa o perfil dos clientes e publica de acordo com suas necessidades. Divulgação de produtos e promoções. Conhece outras marcas concorrentes. Utiliza software de monitoramento.

F Interação com os clientes em potencial através do uso das ferramentas como o chat e compartilhamentos. Busca-se alternativas inovadoras que se adéquam ao público. Publicações que mostram a qualidade e a praticidade na aquisição dos serviços, assim como imagens de eventos realizados, afirmando a qualidade na organização e a seriedade do trabalho. Atenção às variedades e novidades tecnológicas que podem contribuir para a redução de custos ao realizar o marketing dos produtos e para o aumento do fechamento de negócios. Utiliza software de monitoramento.

G Atende de forma direcionada ao público-alvo. Mantém uma relação mais direta com o cliente, conhecendo suas opiniões, desejos e anseios nos comentários. Atenção aos feedbacks. Levase o conteúdo de forma prática, dinâmica com uma linguagem próxima do que ele quer ler, ouvir e assistir.

H Relaciona-se diretamente com a estratégia de marketing previamente estabelecida. Segmenta determinadas publicidades. Publicação dos produtos e serviços, bem como atividades que a empresa realiza. Utilização de mídia que gere curiosidade do público-alvo. Benchmarking.

\footnotetext{
Fonte: Dados da pesquisa (2016)
}

Para as startups entrevistadas as estratégias de comunicação nas redes sociais digitais estão inseridas no plano de marketing da empresa e consiste, basicamente, na análise e diagnóstico do ambiente virtual, planejamento das ações e conteúdo, publicações e monitoramento das mídias, aqui apresentadas como as variáveis. Além disso, as empresas concordam que houve uma melhoria significativa no contato com os clientes e na imagem da 
empresa após ingresso nas redes. E complementam que, o que era uma forma de chamar atenção de clientes e investidores, agora faz parte das atividades cotidianas de comunicabilidade das empresas.

No que se refere à análise e diagnóstico do ambiente virtual, destacam-se: análise do perfil dos clientes, utilização de personas e benchmarking. A partir daí as empresas planejam o conteúdo das publicações, voltadas para divulgação da marca, produtos e serviços, procurando adaptar as campanhas ao perfil dos clientes, às novidades e tendências do mercado. Neste ponto, ainda há quem defina a frequência dos posts e os temas abordados.

\section{CONSIDERAÇÕES FINAIS}

Conforme apresentado as redes sociais digitais são sinônimos de comunicação, tanto para divulgação quanto para atendimento aos clientes. As mídias sociais apresentam a capacidade de gerar a comunicação livre e não apenas unilateral, como na forma tradicional de marketing. Permite que uma startup e seus clientes, ou potenciais clientes, compartilhem ideias, informações, se envolvam em discussões para desenvolver melhores serviços ou produtos, entre tantas outras possibilidades de ações que possam ocorrer de forma online.

Para as startups as redes sociais digitais além de fonte de entretenimento e informação é uma ferramenta de comunicabilidade empresarial, como as próprias variáveis identificadas, são ferramentas de comunicação e relacionamento.

A utilização das redes digitais pelas startups resumem-se a: 1) interagir com os clientes, como plataforma para realização de negócios, como meio de divulgação da empresa e de seus produtos; 2) viabilizar a base para planejar suas ações, nas quais através das informações geradas e fornecidas é possível desenvolver ou redesenhar seus produtos, serviços e conteúdos promocionais; 3) reduzir custos com divulgação menos dispendiosa, mais direta e de maior alcance; e 4) ampliar de maneira exponencial a sua imagem.

Como a própria definição do nome, as startups são empresas iniciantes cujo modelo de negócio caracteriza-se por atingir um número considerável de clientes e gerar lucros em pouco tempo, sem que aja um aumento significativo dos custos, uma vez que encontram-se, geralmente, condicionadas a recursos limitados e intensa concorrência. Dessa forma, a necessidade de chegar aos consumidores e propagar a imagem da empresa com rapidez, oportunizadas pela mobilização de recursos digitais, tornam-se decisivas para o sucesso do empreendimento. 
Nota-se que algumas startups pesquisadas têm um planejamento bem definido, no qual as ações de análise e diagnóstico do ambiente virtual, planejamento das ações e conteúdo, publicações e monitoramento das redes sociais acontecem de forma integrada, garantindo o alcance dos objetivos.

No entanto, fica a sugestão para aquelas que ainda não fazem esse tipo de planejamento que haja um trabalho estruturado, procurando focar no perfil dos clientes e sua percepção a respeito dos produtos e serviços oferecidos pela empresa, identificar temas em alta, direcionar estratégias, expor ativamente nas mídias, controlar e avaliar a participação e credibilidade nas redes com ajuda de um software, por exemplo. A partir daí é possível ajustar suas propostas de comunicação e relacionamento com os clientes aos objetivos do negócio e ao mercado de atuação.

\section{REFERÊNCIAS}

ALBERONE, M. CARVALHO, R. KIRCOVE, B. Sua ideia ainda não vale nada - O guia prático para começar a validar seu negócio. Rio de Janeiro, 2012.

ALVARENGA, C. M. F.. Vantagens/oportunidades das redes sociais virtuais na promoção de negócios. Tese (Mestrado em Gestão das Organizações) - Instituto Politécnico do Cávado e do Ave, Barcelos, 2014.

AMEZCUA, P. M. Redes sociales, mecanismos generadores de reputación organizacional para la Pymes. Universidad \& Empresa No. 22, pp. 131-149, 2012.

ASKOOL, S., JACOBS, A; NAKATA, K. A method of analysing the use of social networking sites in business. In: Cruz-Cunha, M. M., Gonçalves, P., Lopes, N., Miranda, E. M. and Putnik, G. D. (eds.) Handbook of Research on Business Social Networking: Organizational, Managerial, and Technological Dimensions. IGI Global, 2011, pp. 119-139.

BARDIN, L. Análise de conteúdo. 4 ed. Lisboa: Edições 70, LDA, 2009.

BOGDAN, R; BIKLEN, S. Investigação Qualitativa em Educação: Uma Introdução à Teoria e aos Métodos. Portugal: Porto Editora, 2010.

CAPUTO, V. Mais da metade dos brasileiros são usuários da internet. Tecnologia. Exame, 2014. Disponível em: <http://exame.abril.com.br/tecnologia/noticias/mais-da-metadedos-brasileiros-sao-usuarios-da-internet > Acesso em 06 abril de 2016.

CASTELLS, M. A sociedade em rede. São Paulo: Paz e Terra, 2013.

COUlTER, K.; ROGGEVEEN, S. A. Like it or not. Management Research Review, Vol. 35 Iss 9 pp. $878-899,2012$. 
CRUZ-CUNHA, M. M et al. The Perceived Potential of Business Social Networking Sites. International Journal of Web Portals: Volume 4 Issue 1, January, 2012.

DORNELAS, J. C. A (2003). Empreendedorismo corporativo: como ser empreendedor, inovar e se diferenciar em organizações estabelecidas. $9^{a}$ reimpressão - Rio de Janeiro: Elsevier, 2003.

DALMORO, M., et al. Twitter®: Uma Análise do Consumo, Interação e Compartilhamento na Web 2.0. In: Encontro Nacional da Associação de Pós-graduação e Pesquisa em Administração. Rio de Janeiro. Anais...Rio de Janeiro, 2010.

FLICK, U. Desenho da pesquisa qualitativa. Coleção Pesquisa Qualitativa. Porto Alegre: Bookman, Artmed, 2009.

GARDHAMER, S. 4 ways social media is changing business. Mashable.Com, October, 2010. Disponível em: <http://mashable.com/2009/09/22/social-media-business.com>. 2016. Acesso em: 10 abril de 2016.

GERHARDT, T. E.; SILVEIRA, D. T. Métodos de pesquisa. Porto Alegre: Editora da UFRGS, 2009.

GITAHY, Y. O que é uma startup?. Revista Exame, 2011. Disponível em: <http:// http://exame.abril.com.br/pme/noticias/o-que-e-uma-startup/>. Acesso em: 31 de março de 2016.

LONGHI, F. A história da revolução das startups. Imasters, 2011. Disponível em: <http://imasters.com.br/artigo/20027/mercado/a-historia-da-revolucao-das-startups>. Acesso em: 31 de março de 2016.

MINISTÉRIO DA CIÊNCIA, TECNOLOGIA E INOVAÇÃO - MCTI. Saiba tudo sobre o Start-Up Brasil Programa. Disponível em: <http://startupbrasil.org.br/sobre_programa/>. Acesso em: 4 de abr de 2016.

MORAES, R. R. et al. Empreendedorismo Start Up: um Estudo de Caso em uma Empresa de Tecnologia no Estado do Pará. In: Simpósio de Excelência em Gestão e Tecnologia. Rio de Janeiro. Anais...Rio de Janeiro, 2012.

RECUERO, R. Redes sociais na Internet. Porto Alegre: Sulina, 2009.

RIES, E. A startup enxuta: Como os Empreendedores Atuais Utilizam a Inovação Contínua para Criar Empresas Extremamente Bem-sucedidas. São Paulo: Lua de Papel, 2012

ROCHA, T. V., JANSEN, C., LOFTI, E, \& Fraga, R R. O uso das redes sociais na construção do relacionamento com clientes: um estudo de caso múltiplo no Brasil. In: Encontro da Anpad. Rio de Janeiro. Anais...Rio de Janeiro, 2011.

SECRETARIA DE COMUNICAÇÃO SOCIAL - SCS (Brasil). Pesquisa Brasileira de Mídia 2015: hábitos de consumo de mídia pela população brasileira. Brasília: Secom. 
SILVA, D. B. Redes Sociais Virtuais: Um Estudo da Formação, Comunicação e Ação Social. Dissertação (Mestrado em Design e Arquitetura- 2011) - Universidade de São Paulo, São Paulo, 2011.

SOUZA, E. C. L. de. Empreendedorismo: da gênesis à contemporaneidade. In: EGEPE Encontro de Estudos sobre Empreendedorismo e Gestão de Pequenas Empresas. (2005). Curitiba. Anais... Curitiba: Egepe. p. 134-146.

TANENBAUM, A. S. Computer Networks. 5 ed. Seattle: Prentice Hall, 2010.

WALSH, B. The Web Startup Success Guide. Editora Springer-Verlag, EUA, 2009.

YIN, R. K. Estudo de caso: planejamento e métodos. 3 ed. Porto Alegre: Bookman, 2005. 